\title{
Growth of Adsorbed Additive Layer for Further Friction Reduction
}

\section{$\operatorname{AUTHOR}(S)$ :}

Hirayama, Tomoko; Maeda, Masayuki; Sasaki, Yuto; Matsuoka, Takashi; Komiya, Hiroshi; Hino, Masahiro

\section{CITATION:}

Hirayama, Tomoko ...[et al]. Growth of Adsorbed Additive Layer for Further Friction Reduction. Lubrication Science 2018, 31(5): 171-178

\section{ISSUE DATE:}

2018-07-03

URL:

http://hdl.handle.net/2433/244137

\section{RIGHT:}

This is the peer reviewed version of the following article: Hirayama, T, Maeda, M, Sasaki, Y, Matsuoka, T, Komiya, H, Hino, M. Growth of adsorbed additive layer for further friction reduction. Lubrication Science. 2019; 31: 171- 178, which has been published in final form at https://doi.org/10.1002/ls.1420. This article may be used for non-commercial purposes in accordance with Wiley Terms and Conditions for Use of Self-Archived Versions.; The full-text file will be made open to the public on 3 July 2020 in accordance with publisher's 'Terms and Conditions for Self-Archiving'.; This is not the published version. Please cite only the published version.; この論文は出版社版でありません。引用の際には出版社版 をご確認ご利用ください。 
Title: Shear Property of Oil Film Containing Oiliness Additive in Narrow Gap Measured with Newly-Developed Parallel-Disk Viscometer Supported by Aerostatic Bearing

\section{Author Names and Affiliations:}

Tomoko Hirayama $^{1)}$, Shun Shibata ${ }^{2)}$, Tomoyuki Harada ${ }^{2)}$, Yusuke Hashimoto ${ }^{2)}$, Naoki Yamashita $^{1)}$

${ }^{1)}$ Department of Mechanical Engineering and Science, Kyoto University Katsura, Nishikyo-ku, Kyoto 615-8540, Japan

${ }^{2)}$ Graduate School of Science and Engineering, Doshisha University

1-3 Miyakodani, Tatara, Kyotanabe, Kyoto 610-0394, Japan

\section{Corresponding Author:}

Tomoko Hirayama, Prof. Dr. Eng.

Dept. of Mechanical Engineering and Science, Kyoto University

Katsura, Nishikyo-ku, Kyoto 615-8540, Japan

Tel. +81-75-383-3660

E-mail: tomoko@me.kyoto-u.ac.jp

\section{Abstract:}

The shear force of oil film containing an oiliness additive in a narrow gap was measured with a newly-developed parallel-disk viscometer supported by an aerostatic thrust bearing. To evaluate viscometer performance, the shear force of pure base oil was first measured using an oleophobic coated disk. Using the coated disk resulted in interfacial slip between the disk surface and oil, which significantly reduced the shear force compared to that when a non-coated disk was used. Next, the shear force of base oil containing an oiliness additive was measured without using the coated disk. Again it was significantly reduced, especially when the gap was less than $1 \mu \mathrm{m}$. The degree of reduction depended on the oiliness additive used. These results demonstrate that an oiliness additive can cause interfacial slip, resulting in friction reduction even in a hydrodynamic lubrication regime with a submicrometer gap.

\section{Keywords:}

Parallel-disk viscometer, Shear property, Thin oil film, Narrow gap, Oiliness additive, Interfacial slip 


\section{Body of Paper:}

\section{Introduction}

With the strong demand for energy-conserving machines, usage of ultra-low viscosity oil is rapidly becoming more common especially as engine oil for automobiles. The formed oil film is then thinner than that when high viscosity oil is used, reaching boundary lubricated state more easily. Then, the additives mixed into the base oil have come to play a key role in achieving lower friction coefficients and higher wear durability for sliding surfaces. Particularly, oiliness additives generally form an adsorption layer on metal surfaces and thereby reduce friction, especially under lower pressure conditions in the boundary lubrication regime.

The interfacial structure of this adsorption layer has been investigated in various studies over the past 30 or so years, and its state and behavior have been gradually clarified, especially with the recent development of physical and chemical analyzers. For examples, infrared spectroscopy has been commonly used since the early 1990s [1-4], and attenuated total reflection infrared spectroscopy (ATR-IR) in particular has been used to obtain chemical information about adsorbed additive layers on substrate surfaces soaked in lubricant [5,6]. Neutron reflectometry (NR) [7-10], quartz crystal microbalance with dissipation monitoring (QCM-D) [11,12], and frequency-modulation atomic force microscopy (FM-AFM) [13] have been applied to tribological surfaces and have been effectively utilized to facilitate understanding of the mechanisms of adsorption layers formed by oiliness additives.

Recent studies have shown that oiliness additives 'grow' up to several tens of nanometers under tribological conditions [14]. Such findings are changing our conservative knowledge on additives at the solid-liquid interface. However, although the effect of oiliness additives on friction reduction under boundary lubricated conditions has been much discussed, there have been few reports on the effect under hydrodynamic lubrication conditions, especially under narrow gap conditions at the submicrometer level. If the thickness of the oiliness additive layer reaches 10-nm order, it also affects the hydrodynamic lubrication properties, especially in a narrow gap.

We have investigated the shear property of lubricant in a narrow gap by using a newly-developed viscometer with parallel disks supported by an aerostatic bearing. The narrow gap was set at submicrometer level. Two kinds of oiliness additives were mixed into sample lubricant, and their shear force properties between the parallel disks were compared.

\section{Parallel-Disk Viscometer}

\subsection{Structure around Parallel Disks}

To measure the shear force of oil film in a narrow gap, we had to develop a viscometer with a gap at the submicrometer level because most commercial viscometers have comparatively wide gaps (at the submillimeter level at minimum). We needed a 
viscometer with a stable and parallel gap at the submicrometer level that remained fixed during shear force measurement regardless of the shear velocity. The gap had to be adjustable with precise positioning resolution. And it had to be able to precisely measure the shear force of oil film.

A diagram of the viscometer we developed is shown in Figure 1, and the components are listed in Table 1. An enlarged schematic diagram of the key components is shown in Figure 2. As shown in the figure, sample lubricant is injected between the upper specimen (11) and lower disk (21), the main dimensions of which are listed in Table 2. The upper specimen has an aerostatic thrust bearing face in the center (outer diameter $=\phi 22 \mathrm{~mm}$ ) and a simple flat face area in the outer ring area surrounding the bearing area (inner diameter $=\phi 24 \mathrm{~mm}$ and outer diameter $=\phi 30 \mathrm{~mm}$ ), as shown on the left in Figure 3. Air is supplied from the center hole $(\phi 2 \mathrm{~mm})$ to the aerostatic bearing face, which has fan-shaped surface restrictions. The lower disk has a simple flat face area, as shown on the right in Figure 3, and it is set on the lower disk holder. The lower disk holder is supported by a ball bearing to freely rotate and coupled to the elastic-hinge shaft, which has a small diameter column in the middle (5) supported by two leaf springs (18) with unique shapes for achieving high stiffness in the axial direction and low stiffness in the tilting direction. This design enables the lower disk to tilt due to the tilting stiffness of the aerostatic thrust bearing and thereby maintain a parallel relationship with the upper specimen even during rotation.

The gap between the upper specimen and lower disk is controlled by adjusting the air pressure supplied to the aerostatic bearing through the upper disk and/or by adjusting the pushing force generated by an air cylinder from the bottom of the lower disk (19). The gap is determined by the balance between downward force $f_{S}$ generated in the aerostatic bearing and pushing force $f_{b}$ generated by the air cylinder.

For the test, a sample lubricant was injected into the gap between the upper and lower disks only in the outer ring area. The speed-controllable DC motor (31) rotated the hollow shaft (1) connected to the upper disk through pulleys (25)/(30) and a timing belt. Then, the rheological properties of the target oil were estimated by measuring the torque during rotation of the lower disk by a load cell (6), which can measure the force in the circumferential direction when the upper disk rotates. Pushing force $f_{b}$ was measured with a load cell (15) set between the elastic-hinge shaft attachment (14) and the air cylinder.

\subsection{Theory for Load Capacity of Aerostatic Bearing}

The gap between the aerostatic bearing face and the lower disk face was theoretically predicted by calculating the load capacity of the aerostatic bearing by using the Reynolds equation. The aerostatic thrust bearing we used has a complex restriction created by the combination of an inherent restrictor and a surface restrictor. The surface restrictor was theoretically treated by applying equivalent gap theory to the grooved 
region.

The bearing model for the load capacity calculation is shown in Figure 4. The mass flows from area 1 to area 2, from area 2 to area 3 , and area 3 to the atmosphere are respectively expressed as $m_{12}, m_{23}$, and $m_{3 a}$

$$
\begin{gathered}
m_{12}=2 \pi r_{s} h_{e q} C \frac{p_{s}}{\sqrt{R T}}\left[\frac{2 \kappa}{\kappa-1}\left\{\left(\frac{p_{s}^{\prime}}{p_{s}}\right)^{\frac{2}{\kappa}}-\left(\frac{p_{s}^{\prime}}{p_{s}}\right)^{\frac{\kappa+1}{\kappa}}\right\}\right]^{\frac{1}{2}} \\
m_{23}=\frac{\pi h_{e q}^{3}}{12 \mu R T} \cdot \frac{p_{s}^{\prime 2}-p_{g}^{2}}{\ln \left(r_{g} / r_{s}\right)} \\
m_{3 a}=\frac{\pi h_{l}^{3}}{12 \mu R T} \cdot \frac{p_{g}^{2}-p_{a}^{2}}{\ln \left(r_{a} / r_{g}\right)}
\end{gathered}
$$

where $r_{s}, r_{g}$, and $r_{a}$ are the radii of the center hole (the inlet port) in area 1 , the grooved region in area 2 , and the whole bearing area (area 3), and $p_{s}, p_{s}^{\prime}, p_{g}$, and $p_{a}$ are the inlet pressure, the pressure at $r_{s}$, the pressure at $r_{g}$, and the atmospheric pressure, respectively; $h_{e q}$ and $h_{l}$ are the equivalent gaps in areas 2 and 3 , and $h_{e q}$ is calculated using

$$
h_{e q}=\left\{\gamma\left(h_{l}+\delta\right)^{3}+(1-\gamma) h_{l}^{3}\right\}^{1 / 3},
$$

where $\delta$ and $\gamma$ are the groove depth and circumferential area ratio of the grooves. The definitions of the other symbols are shown in the nomenclature. From the mass conservation law,

$$
m_{12}=m_{23}=m_{3 a}
$$

must be satisfied. The pressure distributions $p_{2}$ and $p_{3}$ in areas 2 and 3 can be calculated from the Reynolds equation considering the compressibility of the air flow:

$$
\begin{array}{ll}
\frac{d}{d r}\left(h_{e q}^{3} r \frac{d p_{2}^{2}}{d r}\right)=0 & \text { for area } 2 \\
\frac{d}{d r}\left(h_{l}^{3} r \frac{d p_{3}^{2}}{d r}\right)=0 & \text { for area } 3 .
\end{array}
$$

The boundary conditions are thus

$$
\left.p_{2}\right|_{r=r_{s}}=p_{s}^{\prime}
$$




$$
\begin{gathered}
\left.p_{2}\right|_{r=r_{g}}=\left.p_{3}\right|_{r=r_{g}}=p_{g} \\
\left.p_{3}\right|_{r=r_{a}}=p_{a} .
\end{gathered}
$$

Finally, the load capacity of the aerostatic bearing (= axial force generated by the aerostatic bearing) $f_{s}$ is calculated:

$$
f_{s}=r_{s}^{2} \pi\left(p_{s}^{\prime}-p_{a}\right)+\int_{r_{s}}^{r_{g}} 2 \pi\left(p_{2}-p_{a}\right) r d r+\int_{r_{g}}^{r_{a}} 2 \pi\left(p_{3}-p_{a}\right) r d r .
$$

The gap between the aerostatic bearing face and lower disk is determined by the force balance between downward force $f_{s}$ generated in the aerostatic bearing and pushing force $f_{b}$ generated by the air cylinder.

\section{Performance Evaluation}

\subsection{Comparison between Experimental and Theoretical Gaps}

Before the shear force measurement of sample liquids, the gap between the flat face of the outer ring area on the upper specimen and the lower disk $c_{r 0}$ should be determined for each pushing force $f_{b}$. We first determined the gap on the basis of the shear force of pure base oil, for which the viscosity is known. If the viscosity of the base oil is assumed to be constant regardless of the gap, the gap can be predicted from

$$
c_{r 0}=\frac{\eta \cdot 2 \pi \omega}{f_{0}} \cdot \frac{r_{1}^{3}-r_{0}^{3}}{3},
$$

where $r_{1}$ and $r_{0}$ are the outer and inner radii of the outer ring area on the upper specimen, and $f_{0}$ is the measured shear force. If the force measured by the load cell (6) for the circumferential direction is expressed as $f_{\text {rot }}$, the relationship between $f_{0}$ and $f_{\text {rot }}$ is

$$
f_{0}=\frac{4}{3} \cdot \frac{r_{1}^{3}-r_{0}^{3}}{r_{1}^{4}-r_{0}^{4}} \cdot l \cdot f_{r o t},
$$

where $l$ is the distance from the rotation center to the pushing point of the load cell (6).

In the test, two kinds of poly-alpha-olefins, PAO30 and PAO63, were used as the pure base oils. Their viscosities at $30^{\circ} \mathrm{C}$ (37.9 and $80.0 \mathrm{cP}$, respectively) were used as the values of $\eta$ for the calculation of gap $c_{r_{0}}$ using equation (12). The air pressure $p_{s}$ supplied to the aerostatic bearing was kept constant at $0.27 \mathrm{MPa}$. The test procedure is as follows.

(1) The certain pushing force by the air cylinder from the bottom was applied.

(2) The constant air pressure for the aerostatic bearing was supplied.

(3) Enough volume of lubricant was supplied to the gap between the upper specimen 
and lower disk by a microsyringe.

(4) The motor was started to run at the maximum speed and the situation was kept for 10 minutes as running-in time until the temperature became stable.

(5) The test was started; the rotational speed was slowed down every 10 seconds, and then the shear force was measured for each rotational speed. The total test time was 4 minutes at maximum.

The measured shear forces for each base oil for various values of $f_{b}$ are shown in Figure 5. The shear force was proportional to the rotational speed. This means two important facts; First is that the gap between the upper specimen and lower disk remained almost constant regardless of the rotational speed during the test. Second is that the viscosity of oil was kept constant, that is, the temperature of oil film was kept during the test after running-in time. The estimated temperature from the representative shear force was about $30^{\circ} \mathrm{C}$ regardless of gap and oil viscosity within our experimental conditions because the heat capacities of upper specimen and lower disk are enough to keep the temperature during the test. On these facts, the gaps $c_{r_{0}}$ determined using equation (12) are shown in Figure 6. The minimum gap was about $0.5 \mu \mathrm{m}$, meaning that a submicrometer gap can be obtained by using the appropriate pushing force.

The average gap is plotted in Figure 7 for each pushing force using theoretical curves calculated using equation (11) for three values of airflow contraction coefficient $C$ at the inlet port. The optimum value of $C$ was 0.32 , which is in line with the values calculated in previous studies. This means that the gap can be controlled by adjusting the pushing force generated by the air cylinder and that its value can be predicted by using equation (12) with the value of $C$ set to 0.32 .

To verify the value of the gap predicted from theory, we used optical interferometry to directly measure the gap between the flat face area of the upper specimen and lower disk, as shown in Figure 8. A 20-nm-thick chromium film had been previously deposited on the face of the lower disk by sputtering to form a half mirror. A filtered dichroic laser emitting red light at $670 \mathrm{~nm}$ and green light at $550 \mathrm{~nm}$ was irradiated into the gap from a xenon stroboscopic light source to measure the oil film thickness and to observe the oil film shape.

Before the test, we first established the table showing the relationship between the gap and fringe color. Then we prepared a steel ball with the diameter of $S \phi 3 / 8$ inch, and the ball was pushed to the chromium-coated lower disk with sandwiching PAO30 under $5 \mathrm{~N}$. Then, we measured the radius of each fringe $r$ observed by the dichroic laser and the fringe colors (black, green, yellow, red) corresponded to the gap length $h$ by the equation of 


$$
h=\frac{a P_{\max }}{E^{\prime}}\left\{-\left(2-\frac{r^{2}}{a^{2}}\right) \cos ^{-1} \frac{a}{r}+\left(\frac{r^{2}}{a^{2}}-1\right)^{\frac{1}{2}}\right\},
$$

where $a, P_{\max }$ and $E^{\prime}$ are contact radius, maximum Hertz pressure and equivalent Young's modulus, respectively.

The gap lengths estimated from the measured shear force and those estimated from the optical interferometry are plotted in Figure 9 for PAO30 as the sample liquid. The gap length measured by the optical interferometry was estimated by corresponding the fringe color to the table previously established. Then, the fringe order was carefully judged from the prev-and-next colors when the pushing load was slightly changed higher and lower.

The gap lengths from the two estimates are in good agreement. A typical interferometric image captured during the test is shown on the right in Figure 9. The fringe color alternated repeatedly between red and green as the rotational speed of the upper specimen was increased. This means that the gap was almost kept to be parallel and that the values predicted using equation (12) are sufficiently accurate.

\subsection{Shear Property when Oleophobic Coating was Applied}

To determine whether the measured shear force changes with the surface energy of the top of the lower disk, we applied an oleophobic coating to the top surface of the lower specimen. Previous studies have shown that interfacial slip occurs when an oleophobic coating is applied to a sliding surface. We prepared a resin coating agent containing fluorine (Durasurf DS-5935SH, Harves Co., Ltd.) and formed an oleophobic monolayer film on the surface of the lower disk by dipping. The dipping process was conducted by a simple dip coater with a constant pull-up velocity. After the dipping process, the lower disk was heated at $100^{\circ} \mathrm{C}$ for 1 hour by oven. The coating thickness was estimated by ellipsometer as $4-6 \mathrm{~nm}$ at the several points, so the coated layer was confirmed as homogeneous.

The contact angle of lower disk was measured by a contact angle meter (Drop Master 401, Kyowa Interface Science Co., Ltd.). Images illustrating contact angle (C.A.) measurement are shown in Figure 10; PAO30 was used as the dropped liquid. The contact angle ranged from $13^{\circ}$ to $66^{\circ}$ after treatment. The variation of contact angle was $\pm 1^{\circ}$ at maximum. The measured surface roughness after film formation was the same as that before treatment.

The shear forces for various gaps for PAO30 with non-coated and coated disks are plotted in Figure 11. The difference in shear force between using non-coated and coated surfaces increased as the gap became narrower though each shear force was almost proportional to the rotational speed. When the gap was assumed to be fixed in accordance with Figure 7, the 'apparent viscosity' could be determined by 
transformation of equation (12):

$$
\eta_{a p}=\frac{c_{r 0} \cdot f_{0}}{2 \pi \omega} \cdot \frac{3}{r_{1}^{3}-r_{0}^{3}} .
$$

The apparent viscosities $\eta_{a p}$ calculated from Figure 11 are shown in Figure 12. They were substantially lower when using the coated disk, especially when the gap was less than $1 \mu \mathrm{m}$. Though the actual viscosity of PAO30 in the gap should not have changed, the decrease in the apparent viscosity was due to 'interfacial slip' on the oleophobic surface.

There have been a lot of papers regarding on the 'interfacial slip' phenomena from the past, and the effect of slip has been discussed especially in the field of surface science. From the viewpoints of molecular interpretation, some reports show that the density of liquid molecules becomes lower on the liquidphobic surface, resulting in interfacial slip, while the density becomes higher on the liquidphilic surface [15-17]. And the interfacial slip of water was widely observed and recognized on the both of micro and macroscopic studies [18-22]. Though the number of reports on the interfacial slip of oil on oleophobic surface is smaller than that for the case of water, similar concepts for the interfacial slip can be applied also for oil/substrate interface when an oleophobic surface is used [23-26]. For example, Yu et al. reported the occurrence of interfacial slip on an oleophobic PFPE surface under high shear rate conditions [26], and the trend of our results agrees well with theirs. The results we obtained demonstrate that the developed viscometer is suitable for evaluating the shear force of a sample liquid with including the effect of interfacial interaction between the surface and liquid, especially in a narrow gap.

\section{Shear Property of Oil Containing Oiliness Additive}

To examine the effect of mixing an oiliness additive into the base oil on the shear force in a narrow gap, we added either palmitic acid or oleic acid to the PAO30 base oil. The concentration of each additive was 0.3 mass $\%$. We injected the oil into the gap between the flat area of the upper specimen and lower disk and then started the motor to rotate the hollow shaft. The air pressure $p_{s}$ supplied to the aerostatic bearing was kept constant at $0.27 \mathrm{MPa}$.

The measured shear forces are plotted in Figure 13, and the apparent viscosity calculated using equation (15) for each gap is shown in Figure 14. We can see from Figure 13 that the shear force was lower when the oil contained an oiliness additive, especially when the gap was narrower. This result is similar to that when the oleophobic surface was used, which means that interfacial slip occurs when an oil containing an oiliness additive is used. In addition, our finding that the shear force was almost proportional to the rotational speed even when an additive was used is interesting and 
important because it means that the factor determining whether interfacial slip occurs is not the 'shear rate' but the 'absolute size of the gap'. Moreover, these results show that the effect of interfacial slip depends on the oiliness additive; the apparent viscosity for the case using palmitic acid was lower than that for the case using oleic acid. The slip length for the case using palmitic acid was about $0.44 \mu \mathrm{m}$, while that for the case using oleic acid was about $0.24 \mu \mathrm{m}$, at $c_{r 0}=0.59 \mu \mathrm{m}$, calculated on the general definition of slip length [26].

We finally discuss on where the interfacial slip face is. One possibility is to slip in the boundary layer formed by the acid molecules. Some of recent observations showed that the fatty acid molecules take multilayered structure on the metal surfaces in lubricant [13]. The adsorption of palmitic acid into a metal surface is known to be higher than that of oleic acid because the former has a straight chain while the latter has a flexed one due to the existence of a double bond, and a difference in adsorption properties may be appeared in our test. Figure 15 shows the cross-sectional images of the interface between the $\mathrm{Cu}$ substrate and lubricant captured by FM-AFM (SPM-8000FM, Shimadzu Corp.), as reference. Then, the base oil was hexadecane and the concentration of acid was 0.01 mass $\%$. The palmitic acid molecules took clear multilayered structure while the oleic acid did not multilayered structure but one-layered structure with a constant thickness (The thickness was approximately 6.8 $\mathrm{nm}$ on the both lines of A-B and C-D on the assumption that the bright area corresponds to the boundary layer.) It indicates that the difference of interfacial structure of boundary layer formed from additive may affect the slip length, resulting in the difference of shear force properties under hydrodynamic lubricated condition, that was clearly appeared especially when the gap was narrower.

\section{Conclusion}

The viscometer we have developed has an aerostatic thrust bearing supported by parallel disks and is able to measure the shear force of a sample liquid in a submicrometer gap. The results obtained are summarized as follows.

- The gap in the viscometer can be theoretically estimated as shown by calculation based on the shear force of the base oil and by optical interferometry.

- Applying an oleophobic coating to the top surface of the lower disk reduced the measured shear force, especially when the gap was narrower, compared to the measured shear force when a non-coated surface was used. This shows that interfacial slip occurs on an oleophobic surface, resulting in shear force reduction.

- Adding an oiliness additive to the base oil reduced the shear force, especially when the gap was narrower. The reduction ratio depended on the additive; it was larger for palmitic acid than for oleic acid.

\section{Acknowledgments}


This study was supported by JST PRESTO (Grant No. JPMJPR13C9) and JSPS KAKENHI (Grant No. 26289030). The authors are grateful to Pneumatic Servo Controls, Ltd. for providing the special leaf springs used to support the elastic-hinge shaft and for their helpful advice. 


\section{References}

[1] Hu Z-S, Hsu SM, Wang PS. Tribochemical and Thermochemical Reactions of Stearic Acid on Copper Surfaces Studied by Infrared Microspectroscopy. Tribol. Trans 1992; 35(1): 189-193.

[2] Willermet PA, Carter III RO, Boulos EN. Lubricant-derived tribochemical films An infra-red spectroscopic study. Tribol. Int. 1992; 25(6): 371-380.

[3] Sun J-X, Hu Z-S, Hsu SM. The Effect of Concentration, Solvent, and Temperature on Aggregation of a Commercial Calcium Sulfonate Additive as Studied by FTIR and Light Scattering Techniques. Tribol. Trans. 1997; 40(4): 633-638.

[4] Cann PM, Spikes HA. In-Contact IR Spectroscopy of Hydrocarbon Lubricants. Tribol. Lett. 2005; 19: 289-297.

[5] Piras FM, Rossi A, Spencer ND. Growth of Tribological Films: In Situ Characterization Based on Attenuated Total Reflection Infrared Spectroscopy. Langmuir 2002; 18(17): 6606-6613.

[6] Piras FM, Rossi A, Spencer ND. Combined in situ (ATR FT-IR) and ex situ (XPS) Study of the ZnDTP-Iron Surface Interaction. Tribol. Lett. 2003; 15(3): 181-191.

[7] Hirayama T, Torii T, Konishi Y, Maeda M, Matsuoka T, Inoue K, Hino M, Yamazaki D, Takeda M. Thickness and density of adsorbed additive layer on metal surface in lubricant by neutron reflectometry. Tribol. Int. 2012; 54: 100-105.

[8] Kalin M, Simič R, Hirayama T, Geue T, Korelis P. Neutron-reflectometry study of alcohol adsorption on various DLC coatings. App. Surf. Sci. 2014; 288(1): 405-410.

[9] Simič R, Kalin M, Hirayama T, Korelis P, Geue T. Fatty Acid Adsorption on Several DLC Coatings Studied by Neutron Reflectometry. Tribol. Lett. 2014; 53(1): 199-206.

[10] Lin B, Zhu H, Tieu AK, Hirayama T, Kosasih B, Novareza O. Adsorbed Film Structure and Tribological Performance of Aqueous Copolymer Lubricants. Wear 2015; 332-333: 1262-1272.

[11] Coles JM, Chang DP, Zauscher S. Molecular mechanisms of aqueous boundary lubrication by mucinous glycoproteins. Current Opinion in Colloid \& Interface Science 2010; 15(6): 406-416.

[12] Hakala TJ, Laaksonen P, Saikko V, Ahlroos T, Helle A, Mahlberg R, Hähl H, Jacobs K, Kuosmanen P, Linder MB, Holmberg K. Adhesion and tribological properties of hydrophobin proteins in aqueous lubrication on stainless steel surfaces. Royal Society of Chemistry 2012; 2: 9867-9872.

[13] Hirayama T, Kawamura R, Fujino K, Matsuoka T, Komiya H, Onishi H. Cross-Sectional Imaging of Boundary Lubrication Layer Formed by Fatty Acid by 
Means of Frequency-Modulation Atomic Force Microscopy. Langmuir 2017; 33(40): 10492-10500.

[14] Hirayama T, Maeda M, Sasaki Y, Matsuoka T, Komiya H, Hino M. Growth of Adsorbed Additive Layer for Further Friction Reduction. Lubrication Science 2018; https://doi.org/10.1002/ls.1420.

[15] Sendner C, Horinek D, Bocquet L, Netz RR. Interfacial Water at Hydrophobic and Hydrophilic Surfaces: Slip, Viscosity, and Diffusion. Langmuir 2009; 25(18): 10768-10781.

[16] Steitz R, Gutberlet T, Hauss T, Klösgen B, Krastev R, Schemmel S, Simonsen AC, Findenegg GH. Nanobubbles and Their Precursor Layer at the Interface of Water Against a Hydrophobic Substrate. Langmuir 2003; 19 (6): 2409-2418.

[17] Maccarini M, Steitz R, Himmelhaus M, Fick J, Tatur S, Wolff M, Grunze M, Janecek J, Netz RR. Density depletion at solid-liquid interfaces: a neutron reflectivity study. Langmuir 2007; 23(2): 598-608.

[18] Mezger M, Sedlmeier F, Horinek D, Reichert H, Pontoni D, Dosch H. On the Origin of the Hydrophobic Water Gap: An X-ray Reflectivity and MD Simulation Study. Journal of the American Chemical Society 2010; 132(19): 6735-6741.

[19] Ahmad K, Zhao X, Pan Y, Wang W, Huang Y. Atomic Force Microscopy Measurement of Slip on Smooth Hydrophobic Surfaces and Possible Artifacts. The Journal of Physical Chemistry C 2015; 119(22): 12531-12537.

[20] Wang C, Wen B, Tu Y, Wan R, Fang H. Friction Reduction at a Superhydrophilic Surface: Role of Ordered Water. The Journal of Physical Chemistry C 2015; 119 (21), 11679-11684.

[21] Choi C-H, Westin KA, Breuer KS. To Slip or Not to Slip: Water Flows in Hydrophilic and Hydrophobic Microchannels. ASME International Mechanical Engineering Congress and Exposition 2002; 557-564.

[22] Pye JE, Wood CE, Burton JC. Precursors to Molecular Slip on Smooth Hydrophobic Surfaces. Phys. Rev. Lett. 2018; 121: 134501.

[23] Kalin M, Polajnar M. The Effect of Wetting and Surface Energy on the Friction and Slip in Oil-Lubricated Contacts. Tribol. Lett. 2013; 52(2): 185-194.

[24] Wong PL, Li XM, Guo G. Evidence of Lubricant Slip on Steel Surface in EHL Contact. Tribol. Int. 2013; 61: 116-119.

[25] Li XM, Guo F, Wong PL. Shear Rate and Pressure Effects on Boundary Slippage in Highly Stressed Contacts. Tribol. Int. 2013; 59: 147-153.

[26] Yu X, Meng Y, Tian Y, Zhang J, Liang W. Measurement of lubricant viscosity and detection of boundary slip at high shear rates. Tribol. Int. 2016; 94: 20-25. 


\section{Nomenclature}

$a: \quad$ Contact radius

$c_{r 0}$ : Gap between the flat face of the outer ring area on the upper specimen and the lower disk

$f_{0}: \quad$ Shear force converted from $f_{\text {rot }}$

$f_{b}$ : Pushing force by the air cylinder

$f_{S}: \quad$ Axial force generated in the aerostatic bearing

$f_{\text {rot }}: \quad$ Circumferential force measured by the load cell (6)

$h_{e q}: \quad$ Equivalent gap in area 2 of the aerostatic bearing

$h_{l}: \quad$ Gap in area 3 of the aerostatic bearing

$l: \quad$ Distance from the rotation center to the pushing point of the load cell (6)

$p_{a}: \quad$ Atmospheric pressure

$p_{g}: \quad$ Pressure at $r_{g}$ of the aerostatic bearing

$p_{i}(i=2,3): \quad$ Pressure in area 2 and 3 of the aerostatic bearing

$p_{s}: \quad$ Inlet pressure for the aerostatic bearing

$p_{s}^{\prime}: \quad$ Pressure at $r_{s}$ of the aerostatic bearing

$r_{0}: \quad$ Inner radius of the outer ring area on the upper specimen

$r_{1}$ : Outer radius of the outer ring area on the upper specimen

$r_{a}$ : Outer radius of area 3 of the aerostatic bearing

$r_{g}: \quad$ Outer radius of area 2 of the aerostatic bearing

$r_{s}: \quad$ Outer radius of inlet port of the aerostatic bearing

$C: \quad$ Airflow contraction coefficient

$E^{\prime}: \quad$ Equivalent Young's modulus

$P_{\max }:$ Maximum Hertz pressure

$R: \quad$ Gas constant

$T: \quad$ Temperature

$\delta: \quad$ Groove depth

$\gamma: \quad$ Circumferential area ratio of the grooves

$\eta: \quad$ Sample oil viscosity

$\eta_{a p}: \quad$ Apparent viscosity calculated from the measured shear force

$\kappa: \quad$ Heat capacity ratio

$\mu: \quad$ Air viscosity

$\omega: \quad$ Rotational speed 


\section{Figure and Table Captions}

Fig. 1 Schematic of newly developed parallel-disk viscometer with submicrometer gap.

Fig. 2 Enlarged diagram of key components in viscometer. Sample lubricant is injected between upper specimen and lower disk. Gap between upper specimen and lower disk is kept parallel by high tilting stiffness of aerostatic bearing fabricated in center of upper specimen. To bring aerostatic bearing into operation, air is supplied from center hole of upper specimen and then exhausted through slot between aerostatic bearing face and outer ring area.

Fig. 3 Upper specimen (left, stainless steel) and lower disk (right, borosilicate glass).

Fig. 4 Definition of symbols for upper specimen.

Fig. 5 Shear forces for two kinds of base oils measured under various pushing forces.

Fig. 6 Gap estimated from shear force properties of base oils. Gap values under constant pushing force were virtually stable regardless of rotational speed and oil viscosity.

Fig. 7 Relationship between pushing force and gap; $C$ is coefficient of airflow contraction at inlet port.

Fig. 8 Optical interferometry setup for direct measurement of gap between flat face area of upper specimen and lower disk surface.

Fig. 9 Gap values estimated from optical interferometry and calculated from shear force, and typical interferometric image captured during test. Both values in graph agree well with theoretical prediction up to $f_{b}=72.5 \mathrm{~N}$.

Fig. 10 Oil droplets for measurement of contact angles for PAO30 on non-coated and oleophobic coated surfaces.

Fig. 11 Shear force properties of PAO30 sandwiched between upper specimen and non-coated/coated lower disk.

Fig. 12 Apparent viscosities of PAO30 calculated from shear force properties measured using non-coated/coated lower disk..

Fig. 13 Shear force properties of pure PAO30 and PAO30 with 0.3-mass\% palmitic/oleic acid.

Fig. 14 Apparent viscosities of oil calculated from shear force.

Fig. 15 Cross-sectional image of $\mathrm{Cu}$ surface/lubricant interface captured by FM-AFM. The base oil was hexadecane and the acid concentration was 0.01 mass $\%$. The detailed information on the capturing method is described in [13]. The substrate was $\mathrm{Cu}$ because the bright area was almost not observed when we used Fe substrate instead of $\mathrm{Cu}$ one.

Table 1 Components of newly developed viscometer

Table 2 Dimensions and specifications of upper specimen and lower disk 
Figures:

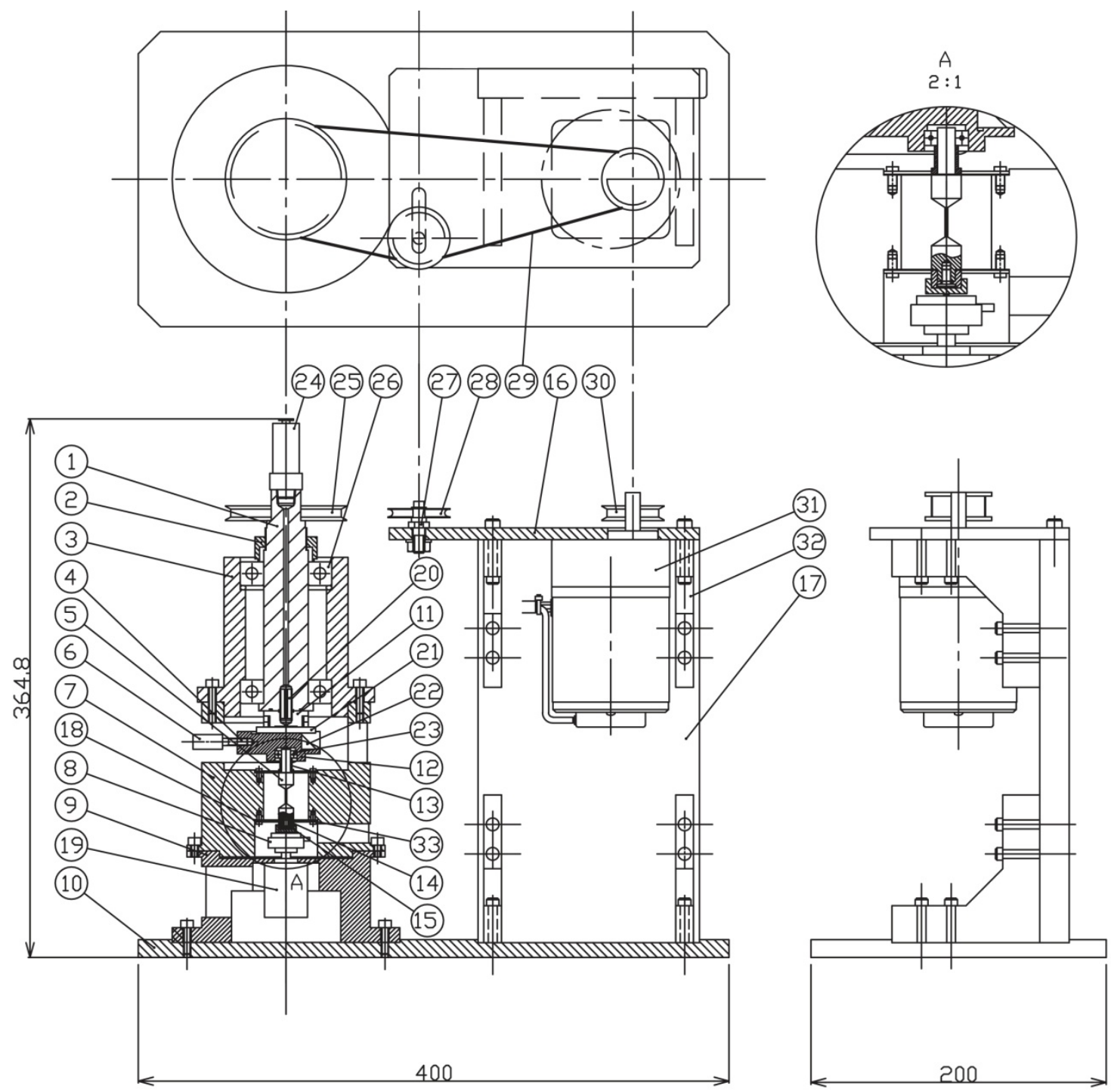

Fig. 1 Schematic of newly-developed parallel-disk viscometer with submicrometer gap. 


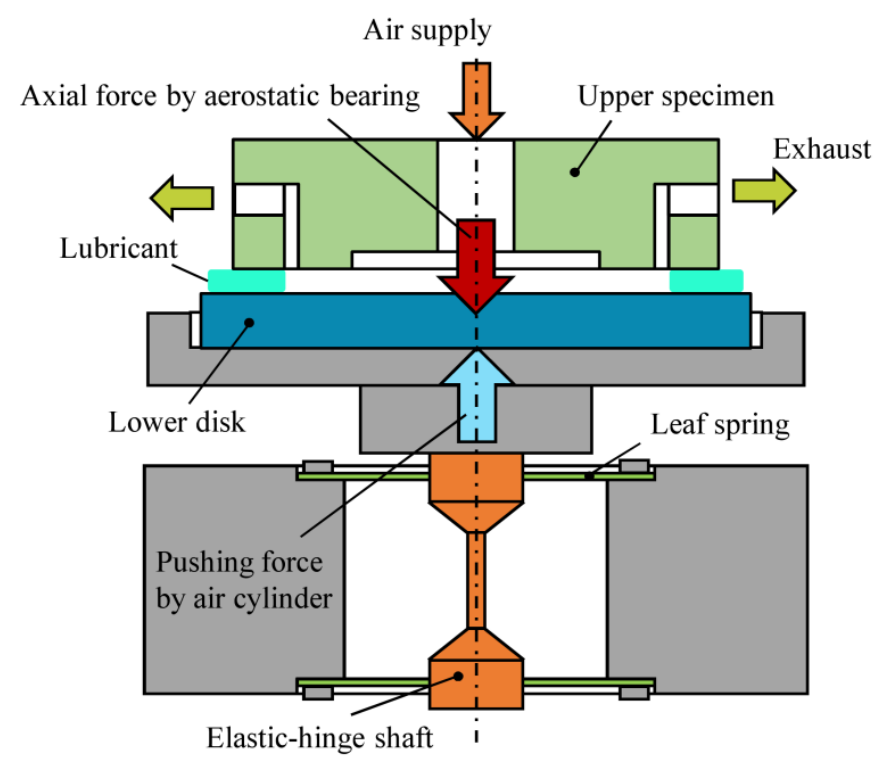

Fig. 2 Enlarged diagram of key components in viscometer. Sample lubricant is injected between upper specimen and lower disk. Gap between upper specimen and lower disk is kept parallel by high tilting stiffness of aerostatic bearing fabricated in center of upper specimen. To bring aerostatic bearing into operation, air is supplied from center hole of upper specimen and then exhausted through slot between aerostatic bearing face and outer ring area.

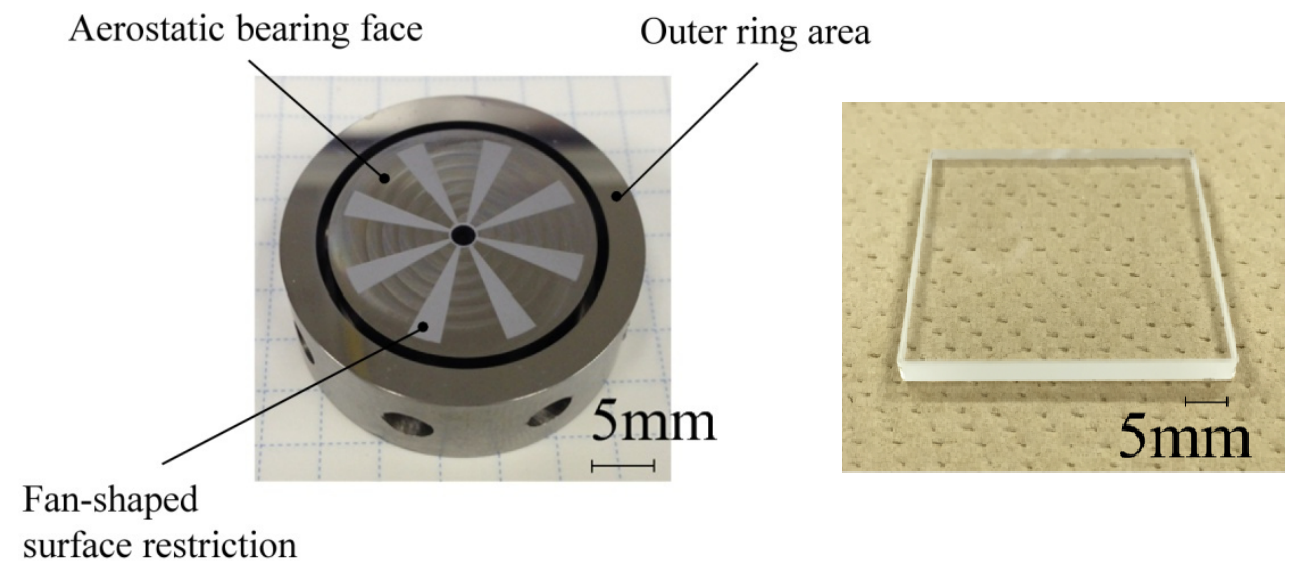

Fig. 3 Upper specimen (left, stainless steel) and lower disk (right, borosilicate glass). 


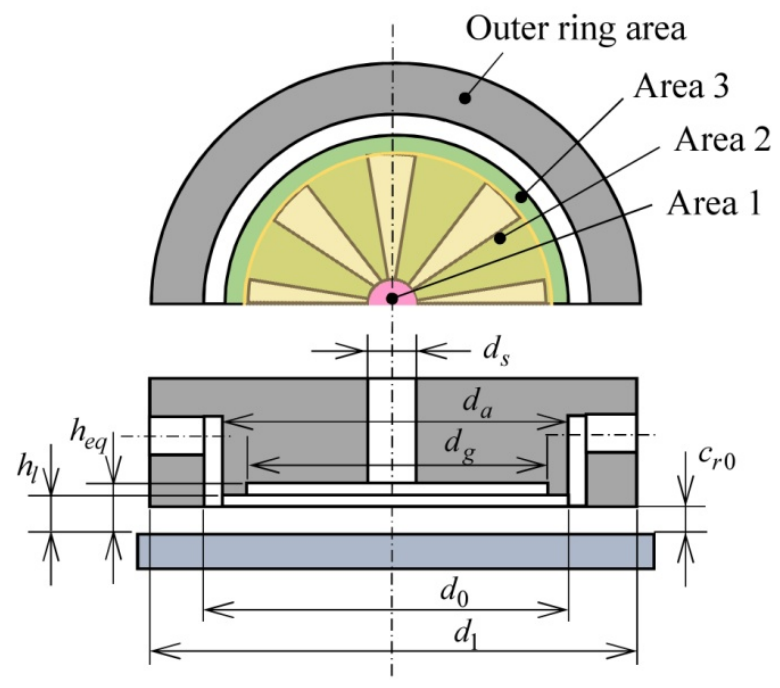

Fig. 4 Definition of symbols for upper specimen.

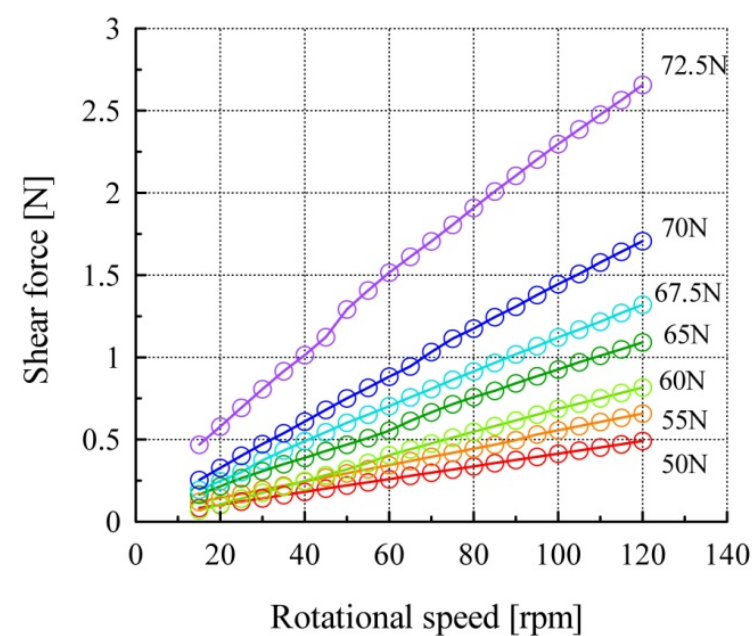

(a) PAO30

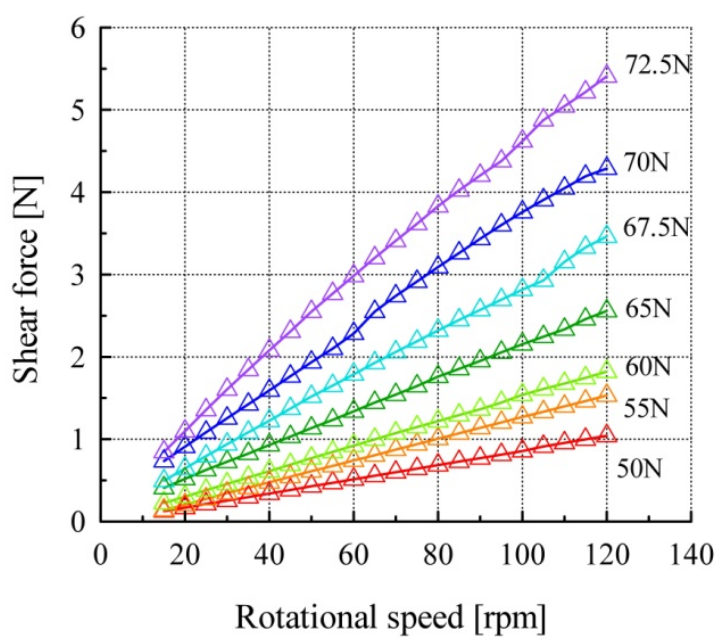

(b) PAO63

Fig. 5 Shear forces for two kinds of base oils measured under various pushing forces. 


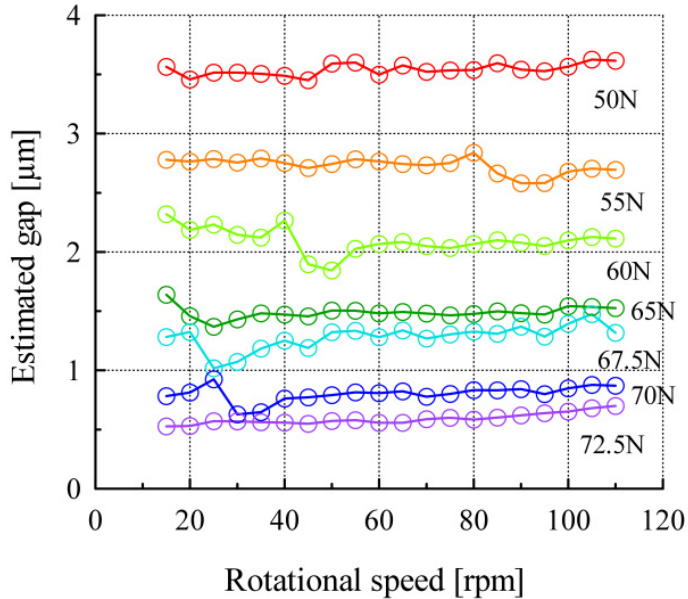

(a) PAO30

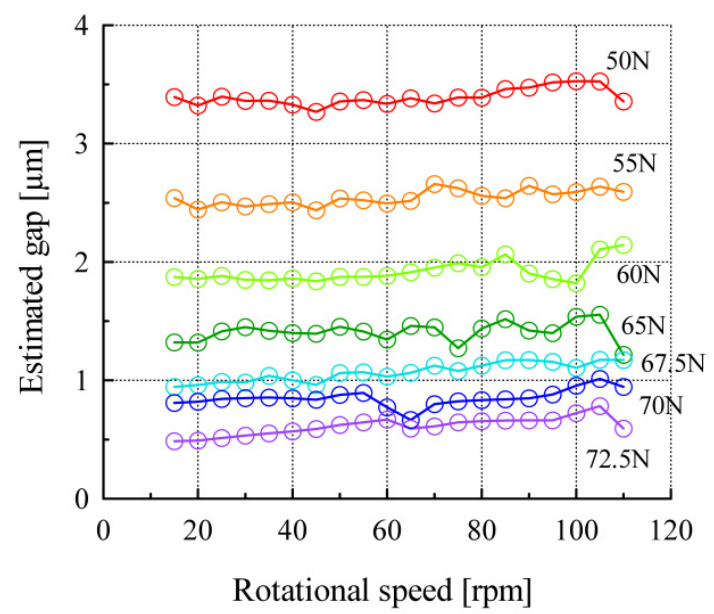

(b) PAO63

Fig. 6 Gap estimated from shear force properties of base oils. Gap values under constant pushing force were virtually stable regardless of rotational speed and oil viscosity.

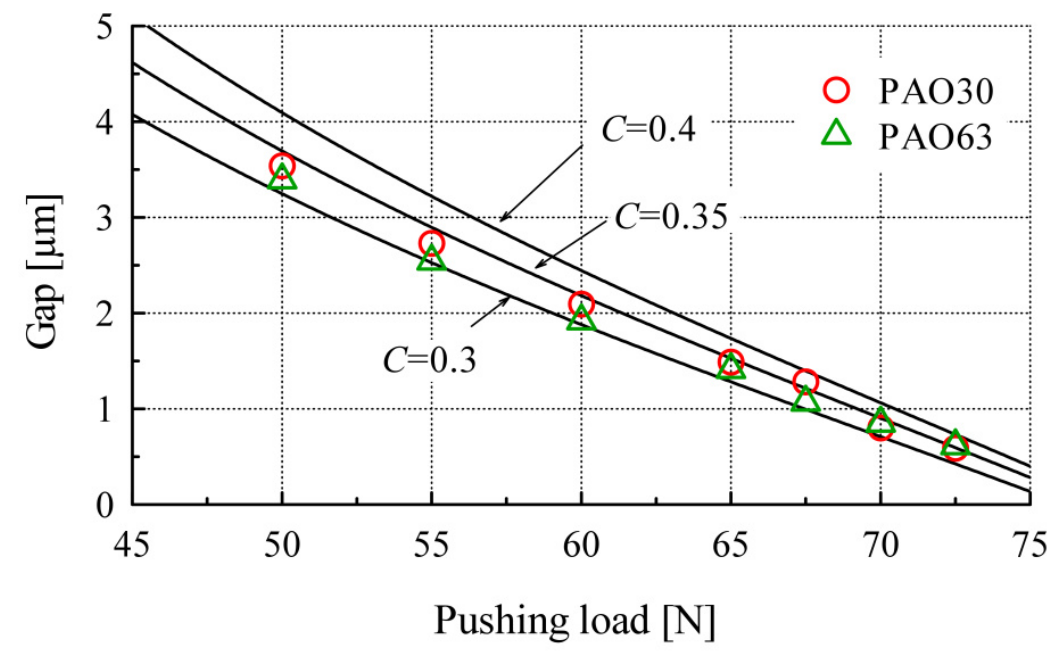

Fig. 7 Relationship between pushing force and gap; $C$ is coefficient of airflow contraction at inlet port. 


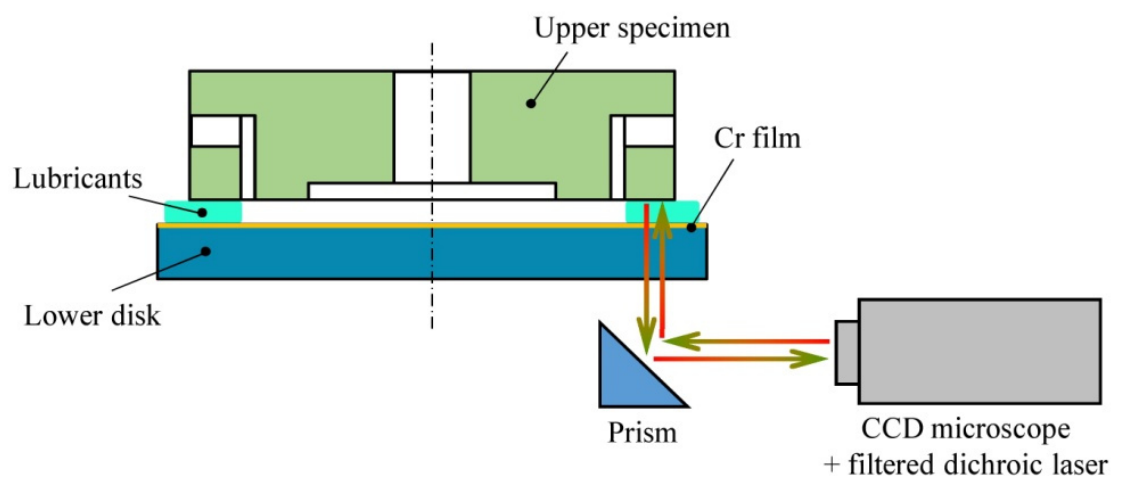

Fig. 8 Optical interferometry setup for direct measurement of gap between flat face area of upper specimen and lower disk surface.
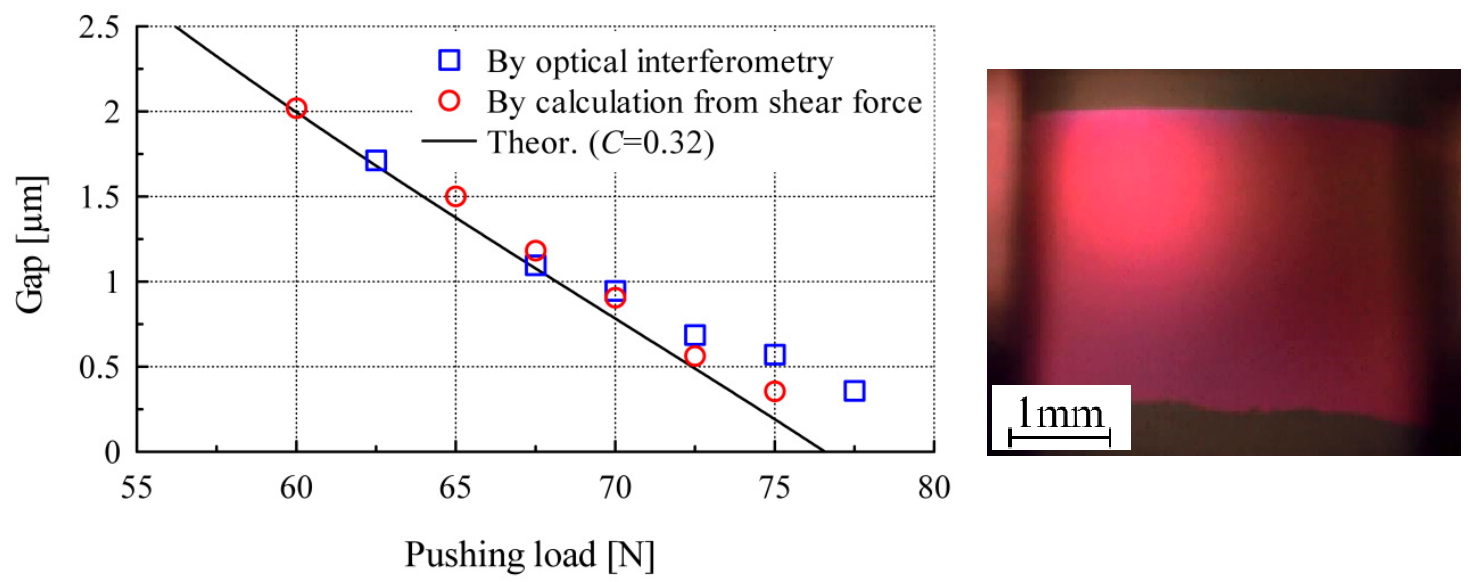

Fig. 9 Gap values estimated from optical interferometry and calculated from shear force, and typical interferometric image captured during test. Both values in graph agree well with theoretical prediction up to $f_{b}=72.5 \mathrm{~N}$. 

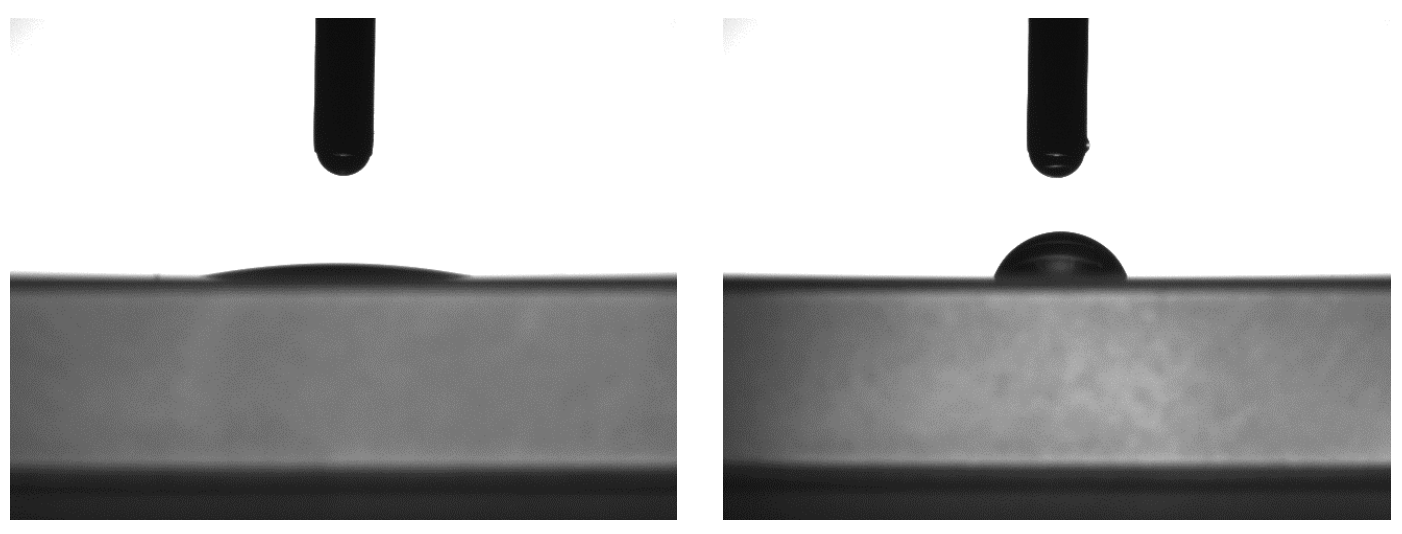

(a) Non-coated surface (C.A. $\left.=13^{\circ}\right)$

(b) Oilphobic coated surface (C.A. $=66^{\circ}$ )

Fig. 10 Oil droplets for measurement of contact angles for PAO30 on non-coated and oleophobic coated surfaces. 


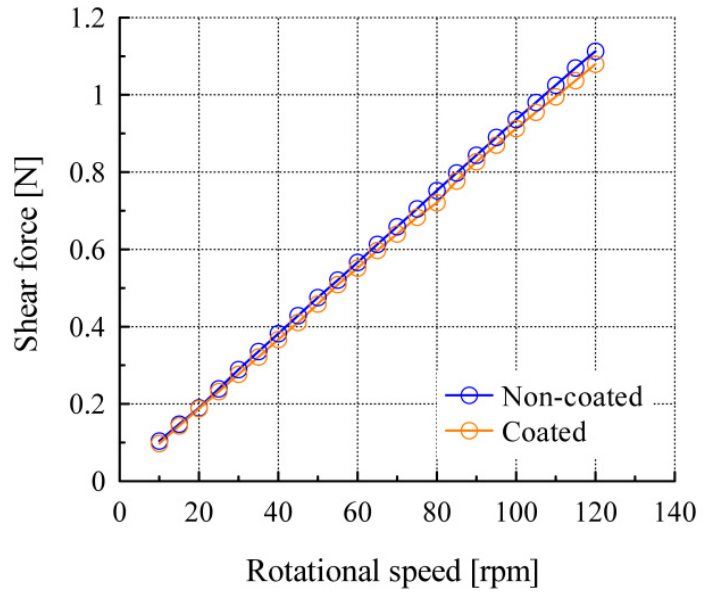

(a) $f_{b}=65 \mathrm{~N}\left(c_{r 0}=1.49 \mu \mathrm{m}\right)$

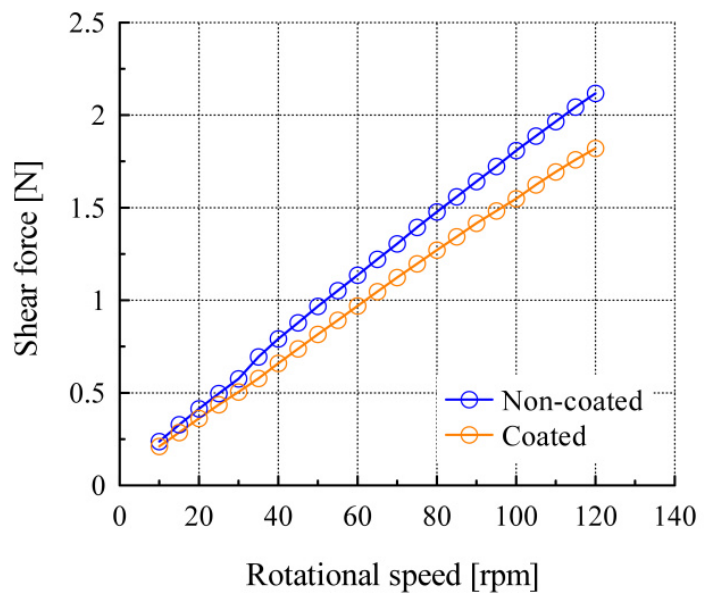

(c) $f_{b}=70 \mathrm{~N}\left(c_{r 0}=0.75 \mu \mathrm{m}\right)$

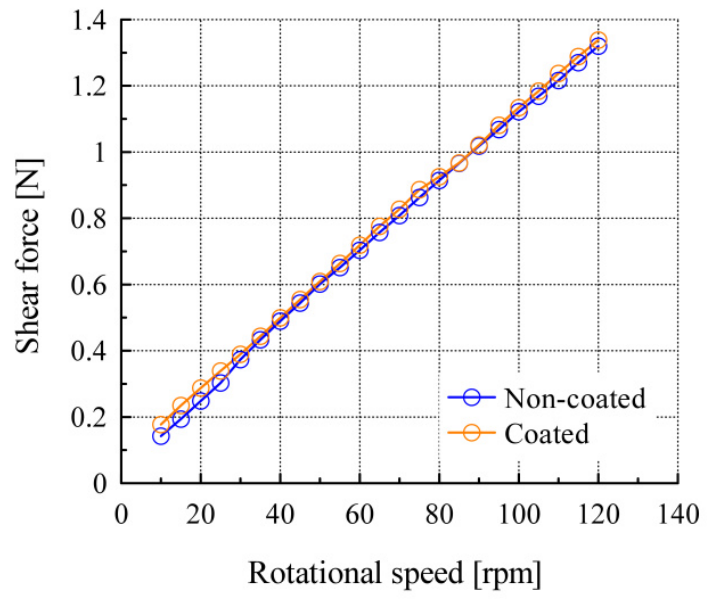

(b) $f_{b}=67.5 \mathrm{~N}\left(c_{r 0}=1.28 \mu \mathrm{m}\right)$

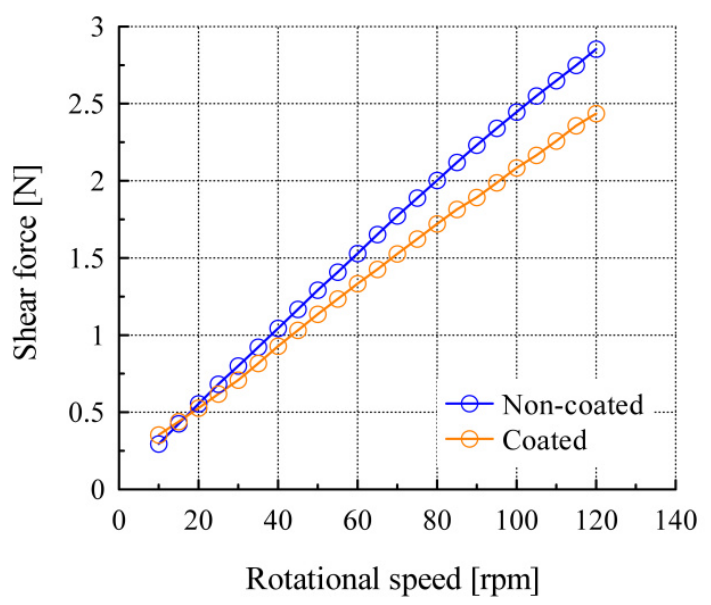

(d) $f_{b}=72.5 \mathrm{~N}\left(c_{r 0}=0.59 \mu \mathrm{m}\right)$

Fig. 11 Shear force properties of PAO30 sandwiched between upper specimen and non-coated/coated lower disk. 


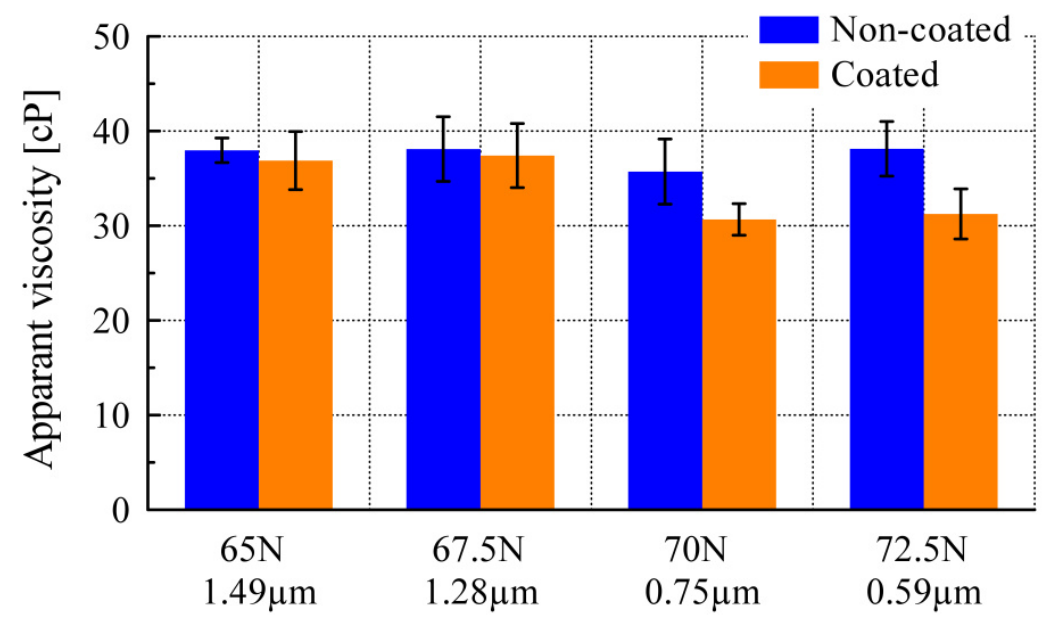

Fig. 12 Apparent viscosities of PAO30 calculated from shear force properties measured using non-coated/coated lower disk. 


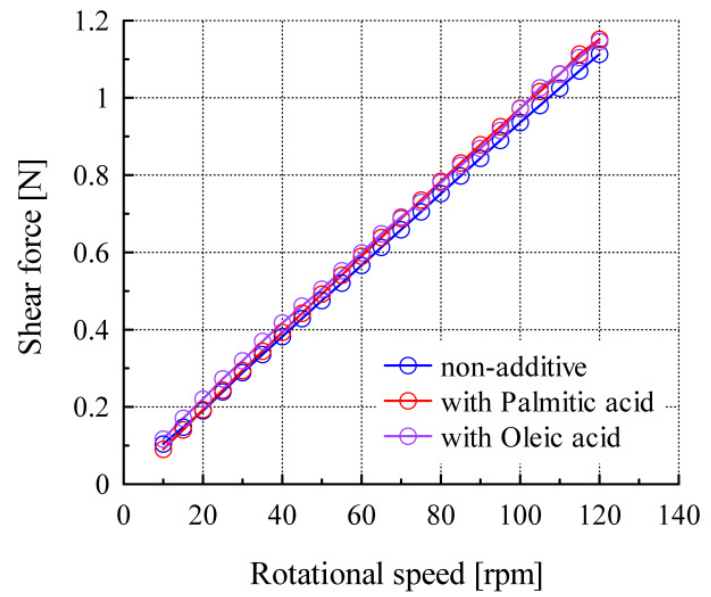

(a) $f_{b}=65 \mathrm{~N}\left(c_{r 0}=1.49 \mu \mathrm{m}\right)$

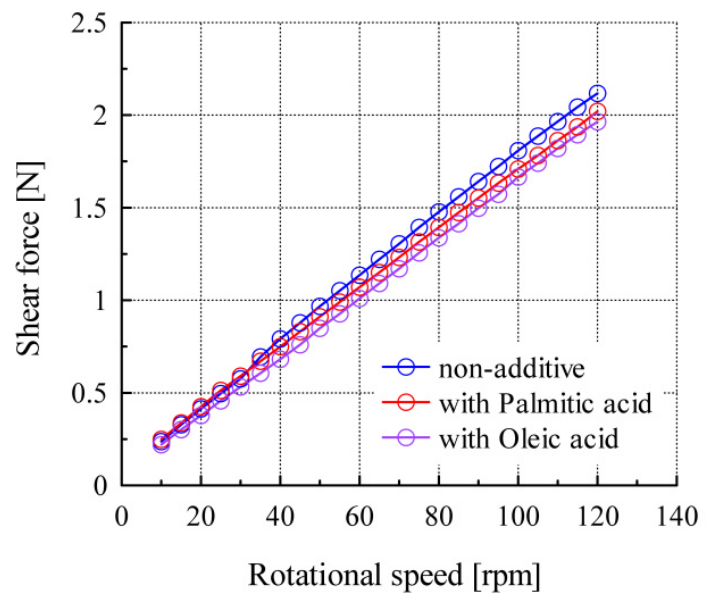

(c) $f_{b}=70 \mathrm{~N}\left(c_{r 0}=0.75 \mu \mathrm{m}\right)$

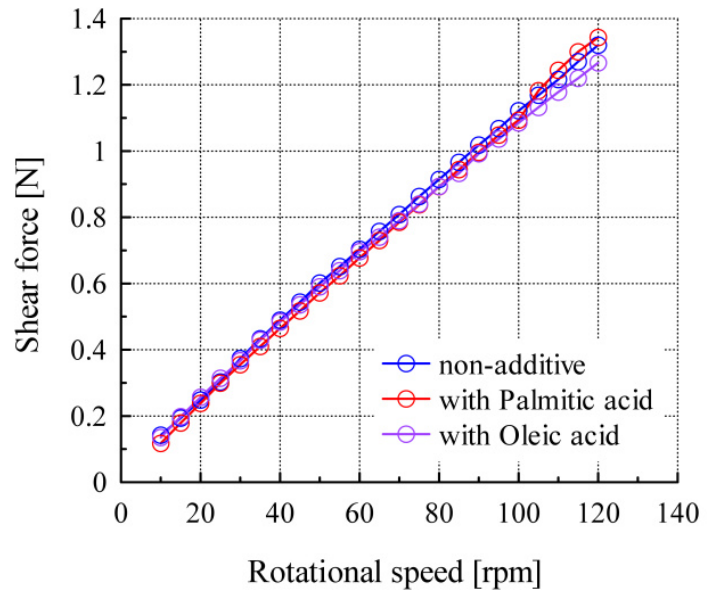

(b) $f_{b}=67.5 \mathrm{~N}\left(c_{r 0}=1.28 \mu \mathrm{m}\right)$

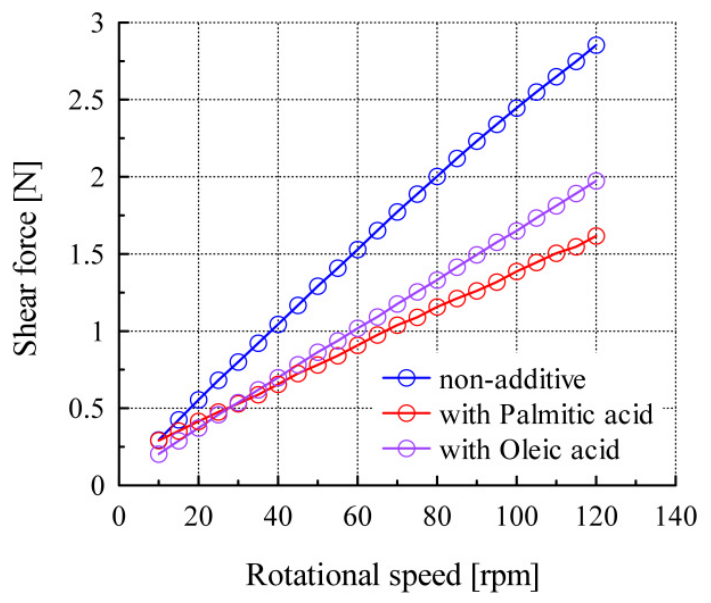

(d) $f_{b}=72.5 \mathrm{~N}\left(c_{r 0}=0.59 \mu \mathrm{m}\right)$

Fig. 13 Shear force properties of pure PAO30 and PAO30 with 0.3-mass\% palmitic/oleic acid. 


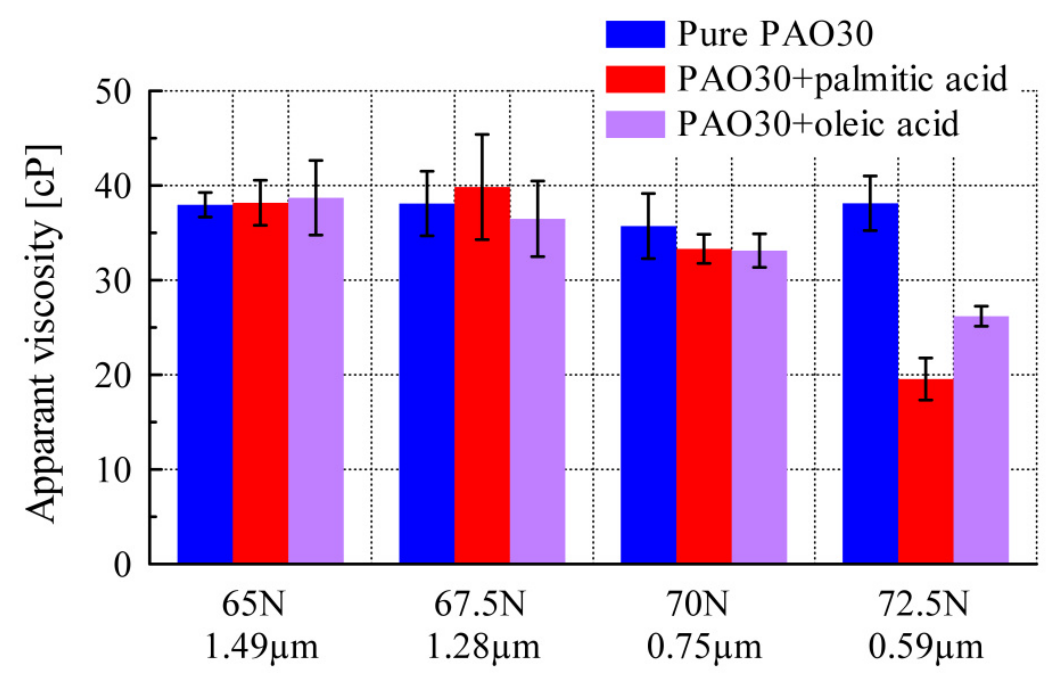

Fig. 14 Apparent viscosities of oil calculated from shear force.

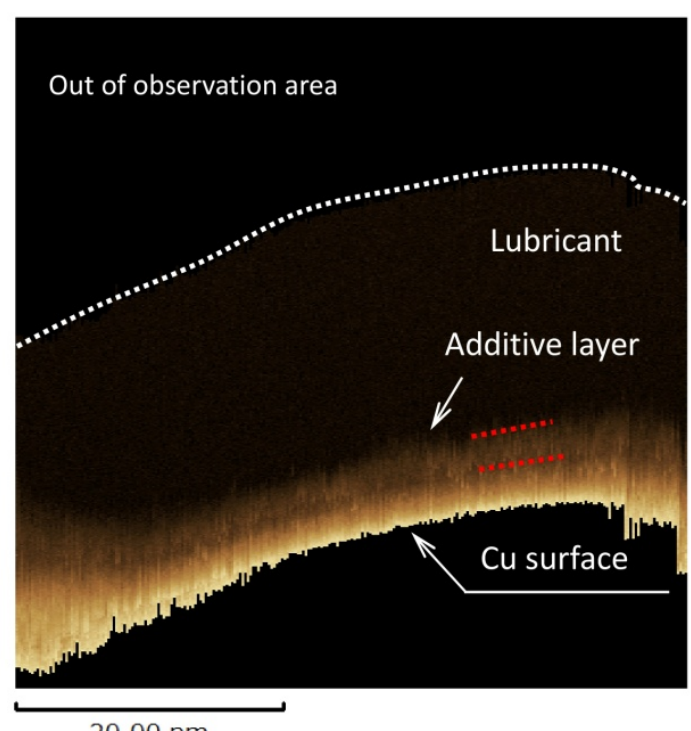

$20.00 \mathrm{~nm}$

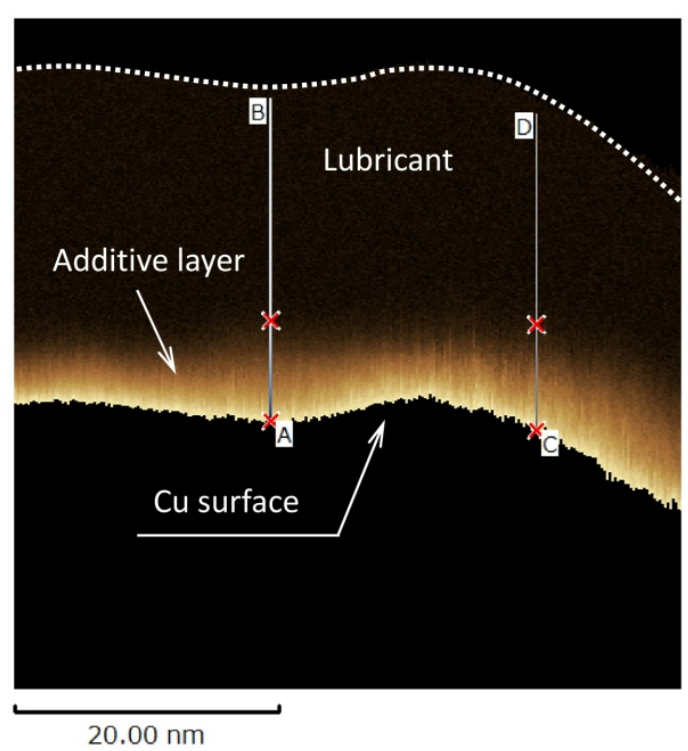

(b) With oleic acid

(a) With palmitic acid [13]

Fig. 15 Cross-sectional image of $\mathrm{Cu}$ surface/lubricant interface captured by FM-AFM. The base oil was hexadecane and the acid concentration was 0.01 mass $\%$. The detailed information on the capturing method is described in [13]. The substrate was $\mathrm{Cu}$ because the bright area was almost not observed when we used Fe substrate instead of $\mathrm{Cu}$ one. 
Tables:

Table 1 Components of newly-developed viscometer.

\begin{tabular}{|c|l|c|l|}
\hline No. & Component & No. & Parts name \\
\hline $\mathbf{1}$ & Main shaft & 18 & Leaf springs \\
\hline $\mathbf{2}$ & Precompression ring & 19 & Air cylinder \\
\hline $\mathbf{3}$ & Upper housing & 20 & Center-holed bolt \\
\hline $\mathbf{4}$ & Bar for torque measurement & 21 & Lower disk \\
\hline $\mathbf{5}$ & Elastic-hinge shaft & 22 & Square prism \\
\hline $\mathbf{6}$ & Load cell for circumferential direction & 23 & Small-sized ball bearing \\
\hline $\mathbf{7}$ & Lower housing & 24 & Rotary joint \\
\hline $\mathbf{8}$ & Load cell stage & 25 & Driven pulley \\
\hline $\mathbf{9}$ & Base housing & 26 & Deep groove ball bearing \\
\hline $\mathbf{1 0}$ & Base plate & 27 & Idler shaft \\
\hline $\mathbf{1 1}$ & Upper specimen & 28 & Idler \\
\hline $\mathbf{1 2}$ & Lower disk holder & 29 & Round belt \\
\hline $\mathbf{1 3}$ & Collar & 30 & Drive pulley \\
\hline $\mathbf{1 4}$ & Hinge shaft attachment & 31 & Speed-controllable DC motor \\
\hline $\mathbf{1 5}$ & Load cell for vertical direction & 32 & Lib \\
\hline $\mathbf{1 6}$ & Top plate & 33 & Leaf spring holder \\
\hline $\mathbf{1 7}$ & Back plate & - & \\
\hline & & & \\
\hline
\end{tabular}


Table 2 Dimensions and specifications of upper specimen and lower disk.

\begin{tabular}{|c|c|c|c|}
\hline \multirow[t]{11}{*}{ Upper specimen } & Material & & SUS440C \\
\hline & Outer diameter of flat area & $d_{1}=2 r_{1}$ & $\phi 30 \mathrm{~mm}$ \\
\hline & Inner diameter of flat area & $d_{0}=2 r_{0}$ & $\phi 24 \mathrm{~mm}$ \\
\hline & Surface roughness of flat area & & $<2 \mathrm{nmRa}$ \\
\hline & $\begin{array}{l}\text { Outer diameter of aerostatic } \\
\text { bearing area }\end{array}$ & $d_{a}=2 r_{a}$ & $\phi 22 \mathrm{~mm}$ \\
\hline & $\begin{array}{l}\text { Outer diameter of grooved } \\
\text { region }\end{array}$ & $d_{g}=2 r_{g}$ & $\phi 20 \mathrm{~mm}$ \\
\hline & Diameter of inlet port & $d_{s}=2 r_{s}$ & $\phi 2 \mathrm{~mm}$ \\
\hline & $\begin{array}{l}\text { Depth of aerostatic bearing face } \\
\text { from flat face }\end{array}$ & $h_{l}-c_{r 0}$ & About $5 \mu \mathrm{m}$ \\
\hline & Number of grooves & & 8 \\
\hline & Groove depth & $\delta$ & $20 \mu \mathrm{m}$ \\
\hline & $\begin{array}{l}\text { Circumferential area ratio of } \\
\text { grooves }\end{array}$ & $\gamma$ & $\begin{array}{l}0.33 \\
\left(=15^{\circ} \times 8 / 360^{\circ}\right)\end{array}$ \\
\hline \multirow[t]{4}{*}{ Lower disk } & Material & & BK7 \\
\hline & Product no. & & $\begin{array}{l}\text { OPB-40S04-10-5 } \\
\text { (Sigma Koki, } \\
\text { Co., Ltd.) }\end{array}$ \\
\hline & Thickness & & $4 \mathrm{~mm}$ \\
\hline & Surface roughness & & $<1 \mathrm{nmRa}$ \\
\hline
\end{tabular}

